\title{
Stimulating Weight Stigma in Future Experimental Designs on Physical Activity - Development and Pilot Validation of a Video Instrument
}

\author{
Johannes Carl ${ }^{a} \quad$ Hendrik K. Thedinga $^{b} \quad$ Stephan Zipfel ${ }^{c} \quad$ Ansgar Thiel $^{b}$ \\ Department of Sport Science and Sport, Friedrich-Alexander University Erlangen-Nürnberg, \\ Erlangen, Germany; ${ }^{b}$ Institute of Sports Science, Eberhard Karls University of Tübingen, \\ Tübingen, Germany; ' Department of Psychosomatic Medicine and Psychotherapy, \\ University Hospital Tübingen, Tübingen, Germany
}

\section{Keywords}

Weight stigma $\cdot$ Manipulation $\cdot$ Video $\cdot$ Validation $\cdot$ Physical activity

\begin{abstract}
Objective: There is a need for more experimental research on weight stigma and physical activity, specifically among men with obesity. Yet, validated procedures are required. The goal of this study was i) to develop a 10-min video instrument for the experimental induction of physical activity-related weight stigma (including a neutral control video), and ii) to collect information with regards to its content, face, construct, and criterion validity. Methods: To ensure content and face validity, two experts gave repeated feedback on the video development. In addition, two novices reviewed the video. Subsequently, we conducted a separate experiment: 60 adult men (18-52 years, 31 with overweight, 29 with normal weight) were randomly assigned to one of the two video conditions, stratified by BMI. Results: After the treatment, the stigma group showed higher scores of negative affect and attitudes against obesity (convergent validity). As expected, there were no differences in measures of depression and general stress (discriminant validity). The BMI of the participants in the stigma group correlated positively with some indicators of negative affect (criterion validity). Conclusion: Our study provides preliminary evidence for the validity of the video tool. Therefore, it can be used in future trials to investigate the effects of weight stigma on physical activity behavior.
\end{abstract}




\section{Introduction}

Obesity is a global phenomenon which is associated with a multitude of health risks [1]. Consequently, there is a high public interest in lowering its prevalence. In this regard, the promotion of physical activity on its own has shown to be an effective strategy for both the prevention and treatment of obesity [2,3]. However, many individuals with obesity are not able to meet official activity recommendation guidelines $[4,5]$, and public health experts have sought to understand the complex reasons for this. Against this background, sociological and psychological research has been trying to identify the psychosocial determinants and barriers which prevent people with obesity from a more physically active lifestyle [6].

In the past decade, weight stigma has attracted increasing attention as a determinant of a number of health-related behaviors [7]. Weight stigma can be described as the 'negative weight-related attitudes and beliefs demonstrated by stereotypes, rejection and prejudice towards individuals because they are overweight or obese' [8]. Individuals with overweight and obesity encounter these biases in many domains of daily life including education, employment, or romantic relationships $[9,10]$, making it difficult for them to avoid the exposure to stereotypes and to escape such discriminative judgments. As a consequence, individuals with obesity experience discrimination in almost all social contexts. For instance, they are frequently disqualified from being hired or are less often nominated for a supervisory position [9]. It can therefore be expected that weight stigma has serious long-term consequences regarding the psychological health of individuals with obesity. Puhl and Heuer [11], for example, consider weight stigmatization as a relevant risk factor for depression, low selfesteem, and body dissatisfaction. Concerning physical activity and exercise contexts, individuals with overweight often face ridicule and teasing during physical activities at school and are confronted with various forms of discrimination and rejection in exercise settings [12].

The investigation of weight stigma and physical activity prompts an important research question as to whether weight stigma has a positive or negative impact on the physical activity behavior of persons with obesity. For instance, how is exercise adherence and daily physical activity (number of daily steps) affected? However, only a small number of studies have addressed this issue in the past, and these few have produced inconsistent and conflicting results: On the one hand, three articles support the very popular assumption among practitioners [13] that weight stigma may raise the recipients' motivation to adopt a healthy lifestyle [14-16]. On the other hand, some studies indicate a negative impact of weight stigma experience on the physical activity behavior of persons with obesity [10,17-19], especially when bias is internalized [16, 20]. In a recent review, Puhl and Suh [21] therefore stated that 'more work in this area is needed to clarify how (...) experiences of stigma influence exercise motivation and behaviours in adults' (p. 185).

Notably, most of the existing research on weight stigma and physical activity has concentrated on children and adult women $[10,15,16,19,22]$. The few experimental studies in this area did also mostly focus on female adults $[16,19]$. However, it would be vital to examine adult men's physical activity behavior as a result of weight stigma for a number of healthbehavioral reasons. Middle-aged men have a higher risk of chronic degenerative diseases, they tend to avoid regular health check-ups and tend to ignore or trivialize health-related risks more than women [23]. Furthermore, their diet is unhealthier, and, importantly, they are less physically active compared to women [24]. Men are thus a very vulnerable group when it comes to the negative consequences of stigma. Nonetheless, the connection between weight stigma and physical activity in men with obesity is highly understudied. The little research that exists in this regard shows for example that experienced weight discrimination is inversely associated with the amount of physical activity in men [17] and that weight bias 
internalization is correlated with exercise avoidance and less exercise [10]. Furthermore, a qualitative interview study by Lewis et al. [25] indicates that adult men with obesity avoid exercise in public exercise settings as a result of weight stigma. Yet, in most of the mentioned studies, physical activity was either not the focus of the interviews, or the studies only included a minor male sample. Hence, the evidence of these findings is too scarce in order to generalize the impact of weight stigma on the physical activity behavior of men with obesity.

One potential reason for the absence of clarity may lie in the fact that most relevant studies relied on simple cross-sectional designs $[10,17,19]$. Under such circumstances, it is difficult to draw causal inferences from a social phenomenon. Consequently, sound experimental setups are required which allow a systematic manipulation of obesity-related stigmatizations and therefore guarantee high internal validity [26]. However, such experimental setups require instruments to stimulate weight stigma, and such instruments need to be languagespecific and culturally appropriate $[27,28]$. Furthermore, in order to examine weight stigma and physical activity behavior, it would be desirable that parts of induced stigma are physical activity-related. Since there is no such tool in the German-speaking area, we postulate the need to develop a suitable instrument for its application in German-speaking countries.

Among the few instruments that have been used in the international weight stigma literature [29], there are two studies which employed reading tasks. Aubie and Jarry [30] created social interaction vignettes in which a female protagonist was either treated respectfully or bullied by two peers because of her weight. Major and colleagues [31] asked participants to read newspaper articles titled either 'Lose Weight or Lose Your Job' or 'Quit Smoking or Lose Your Job'. A further project chose a 'first-hand experience' in which the researchers prevented some participants from joining a shopping experiment due to their body shape [32]. Whereas the two reading studies must be criticized for their poor ecological validity (for a similar criticism, see [33]), the latter could be characterized as unsuited for our research purpose (the cover story and its included stigma form did not directly relate to physical activity).

The most appropriate method in our specific research context was introduced by Schvey et al. [34]. The American research group created a 10-min video manipulation in which the participants were either systematically exposed to clips depicting weight stigmatizations or to neutral clips. This video treatment has three advantages: First, a media format was chosen which can vividly transport impressions and emotions through two different sensory (i.e. visual and auditory) channels $[35,36]$. Second, the medium of videos and films contributes substantially to the presence of weight stigma in our daily life [37]. And third, this setup has already been successfully implemented in the context of other health behaviors such as snack consumption or mental stress [15, 16,34,36]. Notably, Pearl and colleagues [15] already used this video manipulation to study its effects on a form of physical activity. The authors interpreted the mode in which participants moved to another room (stairs vs. taking the elevator) as a proxy indicator for spontaneous physical activity but could not find any differences between both video conditions. However, they only included women in their sample, and the videos did not focus on physical activity-related stigma [15].

As a consequence of the aforementioned gaps in the literature, two goals of our study were therefore:

(1) to develop a video tool in German language for the systematic induction of physical

activity-related weight stigma and

(2) to evaluate its appropriateness for men by means of a separate validation experiment.

In contrast to previous instruments, we planned to include video clips related to physical activity, so it could be specifically used in future experimental designs on physical activity. However, we did not plan to test the effect of the video on participants' physical activity behavior as part of this study. Our goals were the development of a new appropriate instrument and to provide preliminary validation data. 
Carl et al.: Stimulating Weight Stigma in Future Experimental Designs on Physical Activity - Development and Pilot Validation of a Video Instrument

\section{Material and Methods}

\section{Video Development: Ensuring Content and Face Validity}

We decided to take some aspects of validity already into consideration in the development phase of the video. To ensure content validity of the clips, we took the following two steps:

(1) In the run-up to this project, we firstly contacted Dr. Rebecca Puhl and Dr. Mary Himmelstein. As international experts in the field of weight stigma and owners of the above-mentioned English video, they granted us access to their material via an internet sharing platform. This provided us with a clear starting point for selecting similar German videos that portray persons with obesity in a one-sided, pejorative and stigmatizing manner.

(2) We implemented feedback cycles into the video development stage. The authors A.T. and H.K.T. are well experienced in the field of weight stigma and functioned as experts. They watched the raw versions of the videos independently and provided feedback. Where necessary, revisions were done until consensual approval was achieved.

To address face validity, two adults (one male, one female) who were unfamiliar with this topic (having no academic background in psychology, sociology, or sports science) watched the video and were asked to comment on the final versions of the videos.

\section{Video Development: Search and Compilation of Clips}

Stigma Video

From 25\% of the clips that were included in the English stigma video [34], the author J.C. could obtain a corresponding digital version in German. In addition, we looked for appropriate documentaries, TV shows, and internet clips online. The final search, carried out on January 5, 2017, took place on the internet platforms Google Video, Youtube, and Dailymotion. Since we wanted to focus on physical activity-related content, the search was based on the following term combination:

German: (Sport* OR Fitness) AND (Stigma* OR Mobbing) AND (Übergewicht OR Adipositas OR Fett*)

(English Translation: (Exercis* OR fitness) AND (stigma* OR bullying) AND (overweight OR adiposity OR fat*))

After obtaining digital versions of appropriate clips, we cut the different video tracks and merged them into a 10-min video by means of a smooth transition function (Corel VideoStudio ${ }^{\mathrm{TM}}$ Pro X8; Corel Corporation, Ottawa ON, Canada). We decided for ecological validity reasons to include depictions of both men and women. The first video raw version was reviewed by the experts. As a result, video clips which depicted too strong forms of overt discrimination, such as physical aggression, were removed and replaced. Instead, more physical activity- and exercise-related stigma clips were added.

After three feedback rounds, the final video was structured into five topic-related parts (table 1): For the introduction, we had the idea that the participants should be exposed to the notion that obesity has serious consequences but that it is avoidable (triggering internal attribution [38]). Therefore, an interview was selected in which a surgeon listed a range of causes for the occurrence of obesity and emphasized the severity by illustrating its potential consequences (1:02 min). Since we developed the video with a focus on physical activity, the biggest part of the video consisted of several clips in which persons with obesity were shown in a stigmatizing manner in physical activity settings (e.g., problems while exercising, or trainer making negative remarks to a runner with overweight) (4:17 $\mathrm{min})$. In the following sections, the body shape of individuals with adiposity (2:42 $\mathrm{min})$ and their eating behaviors were addressed (1:55 min). The video ended with a short section on people with obesity talking about space problems concerning seats $(0: 38 \mathrm{~min})$. The final version of the video was demonstrated to the novices who confirmed the stigmatizing potential of the material.

\section{Neutral Video}

The purpose for the control condition was to expose participants to a neutral video without affective value. We did not restrict our internet search to a certain topic in order to avoid area-specific emotions. Accordingly, we performed an unstandardized search (no fixed term combination). Table 1 gives an overview of the clips from the various thematic fields (e.g., information on astronomy, sport, law, anatomy, or wine storage). Both experts confirmed the affectively neutral character of the developed video and suggested only one minor modification. Subsequently, the two novices also attested the neutral character of the video. 
Carl et al.: Stimulating Weight Stigma in Future Experimental Designs on Physical Activity - Development and Pilot Validation of a Video Instrument

Table 1. Overview of the sources and contents of both video conditions

\begin{tabular}{|c|c|}
\hline Content/Source & Clip Length \\
\hline \multicolumn{2}{|l|}{ Stigma video (intervention group) } \\
\hline \multicolumn{2}{|l|}{ Part 1: Obesity as a Self-Imposed Disease } \\
\hline Interview with A Surgeon & $1: 02$ \\
\hline \multicolumn{2}{|l|}{ Part 2: Physical Activity Stigma } \\
\hline The Biggest Looser Teens & $0: 33$ \\
\hline Mike and Molly (1) & $0: 37$ \\
\hline Mike and Molly (2) & $0: 46$ \\
\hline Two and a Half Men & $0: 20$ \\
\hline The Biggest Looser & $1: 17$ \\
\hline Hilf mir! (German scripted reality show) & $0: 25$ \\
\hline Fat For Fun & $0: 19$ \\
\hline \multicolumn{2}{|l|}{ Part 3: Eating Behavior Stigma } \\
\hline The Biggest Looser & $0: 57$ \\
\hline Comedy Street (German comedy show) & $0: 46$ \\
\hline Hilf mir! (German scripted reality show) & $0: 12$ \\
\hline \multicolumn{2}{|l|}{ Part 4: Physical Appearance } \\
\hline Gesundheit! Aktiv für die Gesundheit! (German TV show) & $0: 21$ \\
\hline TV Total (German comedy show) & $0: 15$ \\
\hline The Big Bang Theory & $0: 40$ \\
\hline The Biggest Looser & $0: 49$ \\
\hline Mike and Molly & $0: 14$ \\
\hline Luke! Die Woche und ich (German comedy show) & $0: 12$ \\
\hline Fat For Fun & $0: 11$ \\
\hline \multicolumn{2}{|l|}{ Part 5: Troubles with Sitting } \\
\hline Gesundheit! Aktiv für die Gesundheit! (German TV show) & $0: 20$ \\
\hline Galileo (German popular science show) & $0: 04$ \\
\hline Zur Sache! Baden Württemberg (German news show) & $0: 14$ \\
\hline Overall & $10: 34$ \\
\hline \multicolumn{2}{|l|}{ Neutral video (control group) } \\
\hline Documentary on steam engines & $1: 30$ \\
\hline Tent advertisement & $0: 25$ \\
\hline Documentary on seismography & $0: 41$ \\
\hline Study on griffonia & $1: 00$ \\
\hline Summary of a football match $(0: 0)$ & $1: 29$ \\
\hline Advertisement on a vacuum cleaner & $0: 17$ \\
\hline The German constitution & $0: 49$ \\
\hline Documentary on a furnace & $0: 19$ \\
\hline Advertisement on car insurance & $0: 59$ \\
\hline Modes of animal locomotion & $1: 11$ \\
\hline Advertisement on a wine storage system & $0: 35$ \\
\hline The eclipse of the moon & $0: 46$ \\
\hline Overall & $10: 02$ \\
\hline
\end{tabular}

\section{Hypotheses for the Validation Experiment}

In the subsequent validation study, four indicators of construct validity were used to assess the appropriateness and effectiveness of the video instrument: Similar to the results of Schvey et al. [36], we defined a successful manipulation by having an impact on two parameters: the participants' negative affect and their negative attitudes towards obesity. Accordingly, we hypothesized that persons in the stigma group would show significantly greater changes (in both measures) throughout the experiment than participants in the control group, resulting also in higher scores for the intervention group after the treatment (convergent 
validity). On the contrary, the manipulation should have no impact on parameters of depression and stress over the last month because both are conceptualized as situation-independent and hence more stable measures. Accordingly, we expected no group differences in the change throughout the experiment and no group differences at post-test regarding these two parameters (discriminant validity).

Ultimately, we postulated one hypothesis for the assessment of criterion validity based on the assumption that humans have the basic need to maintain a positive social identity [39]. The exposure to weight stigma must be interpreted as a situation that undermines the adoption of effective techniques of self-worth protection [40,41], thus threatening the social identity of people with overweight and obesity $[31,38]$. Consequently, we expected that the more typical representatives of men with obesity (i.e., those with a larger BMI) would react more sensitively to the stigma video than leaner participants. Accordingly, we assumed a positive association in the intervention group between the BMI and indicators of negative affect.

\section{Sample and Procedure of the Validation Experiment}

We executed a separate experimental study in order to test the video manipulation. Since the video is primarily intended to be used in future studies on weight stigma and physical activity with adult men, we validated the developed videos with a male sample. To test for criterion validity, we decided to include male participants with both overweight and normal weight. For the experiment, participants were randomly assigned to one of the two video conditions. Participants' BMI, which we calculated from self-reported height and weight, served as a stratification criterion (two strata: overweight/obese if BMI $\geq 25 \mathrm{~kg} / \mathrm{m}^{2}$ or normal weight if BMI < $25 \mathrm{~kg} / \mathrm{m}^{2}$ ). It was expected that both conditions differ in central validity criteria at least by a pooled standard deviation of 0.8 (corresponding to a large effect [42]). For the calculation of a minimum sample size, a power analysis was performed using the software $G^{*}$ Power Version 3.1.9.2 [43]. According to a two-tailed test (power 0.80 ) for independent samples (t-test), 26 persons were required for each group. Based on these calculations, we decided to recruit 60 male participants aged between 18 and 55 years. In December 2016, our research team sent an e-mail to all students and employees of the University of Tübingen via the university mailing list. In this e-mail, the Institute of Sports Science invited male adults with normal weight or overweight to join a study on video perception and memory. Since we could recruit only 15 individuals with overweight by e-mail, additional efforts were undertaken to specifically reach this target group (distribution of flyers that addressed individuals with overweight, contact to a self-help group for persons with adiposity). With these recruiting strategies, we were finally able to acquire the necessary number of study participants.

The 60 recruited participants were on average 28.48 (SD 8.91) years old. Although almost the whole age range was covered (18-52 years), the overall sample had a right-skewed age distribution (KolmogorovSmirnov test: $\mathrm{p}<0.001$, skewness 1.26). Younger adults between 20 and 30 years were overrepresented (63.3\%). The mean BMI across both groups was 26.83 (SD 5.78) kg/m². Individuals with normal weight had a mean BMI of 22.27 (SD 1.80) kg/m² and individuals with overweight a mean BMI of 31.11 (SD 4.85) kg/m². 33 participants $(55 \%)$ were employed, with more than the half of them being employed part-time $(n=18)$. $75 \%$ were enrolled as students.

After signing declarations of consent, the experiment started with paper-pencil-based questionnaires. Subsequently, a 10-min video was announced. The experiment's supervisor asked the participants to concentrate on the content-related information of the video and indicated that an assessment of the memory capacities would take place afterwards. This deception was necessary to reduce possible reflections on the study's real objective. After the video, participants had to fill out questionnaire-based assessments again. Finally, the experimenter apologized that the memory test had been a deception, handed the participants a compensation of EUR 20.00, and fully debriefed them about the goals of the study.

\section{Instruments}

The pre-video questionnaire started with demographics. The participants had to provide information about their age, educational status, height, weight as well as vocational and student status. In order to test the success of the manipulation stimulated by the video, we made use of a package of established questionnaires before and after the video sequence (table 2), distributed in the following order:

To operationalize negative affect resulting from the video, first we extracted the NA subscale (10 Items) of the German version of the Positive and Negative Affect Schedule (PANAS [44]). Within this instrument, the participants were required to express their current affective state on a 5-point Likert scale (temporal version: 'at this moment'). Before the video, the Cronbach's $\alpha$ value for the NA dimension was 0.67. After the video, a Cronbach's $\alpha$ of 0.75 could be registered. These scores are satisfactory albeit slightly lower than the scores in other studies $[36,44]$. Second, we administered a self-developed questionnaire that is similar to the 
Carl et al.: Stimulating Weight Stigma in Future Experimental Designs on Physical Activity - Development and Pilot Validation of a Video Instrument

Table 2. Overview of instruments used for the assessment of construct validity

\begin{tabular}{|c|c|c|c|}
\hline Construct & $\begin{array}{l}\text { Aspect of construct } \\
\text { validity }\end{array}$ & Hypothesis & Instrument \\
\hline Negative affect & convergent validity & $\mathrm{IG}>\mathrm{CG}$ & $\begin{array}{l}\text { NA subscale of the Positive and } \\
\text { Negative Affect Schedule [44] } \\
\text { Questionnaire for the Assessment of } \\
\text { Video-Related Reactions (QAVR) }\end{array}$ \\
\hline Attitudes against obesity & convergent validity & $\mathrm{IG}>\mathrm{CG}$ & $\begin{array}{l}\text { Short form of the Fat Phobia Scale } \\
\text { [47] }\end{array}$ \\
\hline Depression & discriminant validity & $\mathrm{IG}=\mathrm{CG}$ & $\begin{array}{l}\text { Simplified version of the Beck } \\
\text { Depression Inventory [45] }\end{array}$ \\
\hline $\begin{array}{l}\text { Perceived stress } \\
\text { (in the previous month) }\end{array}$ & discriminant validity & $\mathrm{IG}=\mathrm{CG}$ & Perceived Stress Scale-10 [48] \\
\hline
\end{tabular}

IG = Intervention group (stigma video); CG = control group (neutral video).

instrument used by Schvey et al. [36]. This questionnaire, which will be named 'Questionnaire for the Assessment of Video-Related Reactions' (QAVR) in the following, examined the participants' immediate reactions directly attributable to the video (after the treatment only). Five questions contained the phrase 'This video made me' in conjunction with the attributes 'sad', 'worried', 'ponder', 'angry', and 'upset'. As an additional item, the participants had to judge whether a person with overweight may feel unpleasant when he watches the video. All six questions had to be answered on a 5-point Likert-scale.

To obtain a measure of depressive traits, we used a simplified and unrestricted German version of the Beck Depression Inventory (BDI-V [45]). Despite its small number of 20 items, this questionnaire has shown to have high reliability and validity [46]. Each depressive symptom was self-reported on a 5-point Likert scale. The present analysis revealed a Cronbach's $\alpha$ of 0.87 at baseline and of 0.85 at post-test.

The 14-item short form of the German Fat Phobia Scale (FPS [47]) quantifies negative attitudes against individuals with obesity. In the first step, the participants were asked to imagine a 42-year-old woman with obesity. In the second step, they had to evaluate some further features of this imagined person on a 5-point scale (between two contrasting adjectives). Recent results have provided initial evidence for the reliability as well as construct and factorial validity of the instrument [47]. The internal consistency in our questionnaire was $\alpha=0.88$ before and $\alpha=0.90$ after the video.

The Perceived Stress Scale is a widely accepted self-report scale measuring the amount of perceived stress during the previous month. Klein and colleagues [48] recently published a short version in German with 10 items (PSS-10) that have to be answered with values between 0 and 4 . Their analysis demonstrated promising results for construct validity and internal consistency. The scores of internal consistency in this study were $\alpha=0.86$ at baseline and $\alpha=0.82$ at post-test.

\section{Data Analysis}

Collected data was prepared and analyzed using SPSS Version 24 (IBM, Armonk, NY, USA). Effect size calculations, especially Cohen's d, were conducted with G*Power Version 3.1.9.2 [43]. We applied expectation-maximization(ME)-based imputation techniques [49] to counteract missing values (3.3\%). Data of all 60 participants entered the analysis.

For the assessment of the success of our manipulation, we performed post-video group comparisons between both conditions by means of independent t-tests (equal variances) or Welch's t-tests (unequal variances) with the effect size Cohen's d. Variance homogeneity was determined by conducting Levene's tests. For the instruments that were applied twice, we additionally ran repeated ANOVAs with the betweensubjects factor video condition (stigma vs. neutral) and the within-subjects factor time (before vs. after the video). To determine the impact of the manipulation, main attention was paid to the time-group interaction (effect size $\eta^{2}$ ). 
Table 3. Group characteristics at baseline

\begin{tabular}{|c|c|c|c|c|c|c|c|}
\hline & \multirow[t]{2}{*}{ Range } & \multicolumn{2}{|c|}{$\begin{array}{l}\text { Stigma video } \\
(\mathrm{n}=30)\end{array}$} & \multicolumn{2}{|c|}{$\begin{array}{l}\text { Neutral video } \\
(\mathrm{n}=30)\end{array}$} & \multirow[t]{2}{*}{$\mathrm{t}$} & \multirow[t]{2}{*}{$\mathrm{p}$} \\
\hline & & $\%$ & & $\%$ & & & \\
\hline Student status ${ }^{a}$ & $0-1$ & 77 & & 73 & & $0.089^{b}$ & 0.766 \\
\hline \multirow[t]{2}{*}{ Employment status ${ }^{a}$} & $0-1$ & 57 & & 53 & & $0.067^{b}$ & 0.795 \\
\hline & & M & SD & M & SD & & \\
\hline Age, years & $18-52$ & 27.37 & 8.16 & 29.60 & 9.61 & -0.971 & 0.336 \\
\hline $\mathrm{BMI}, \mathrm{kg} / \mathrm{m}^{2}$ & $18.1-43.4$ & 26.70 & 5.63 & 26.97 & 6.01 & -0.181 & 0.857 \\
\hline Education $^{\mathrm{b}}$ & $1-6$ & 3.50 & 1.11 & 3.30 & 1.02 & $0.679^{a}$ & 0.497 \\
\hline Attitudes against obesity & $22-64$ & 51.47 & 7.41 & 48.53 & 7.96 & 1.48 & 0.145 \\
\hline Negative affect & $10-22$ & 13.19 & 2.97 & 12.77 & 2.65 & 0.536 & 0.564 \\
\hline Depressive symptoms & $23-62$ & 39.40 & 9.44 & 35.17 & 8.38 & 1.83 & 0.071 \\
\hline Perceived stress & $4-30$ & 16.23 & 5.33 & 15.80 & 6.30 & 0.288 & 0.775 \\
\hline
\end{tabular}

$\mathrm{BMI}=$ Body mass index; $\mathrm{M}$ = mean; $\mathrm{SD}$ = standard deviation; Independent, two-tailed t-tests between both conditions.

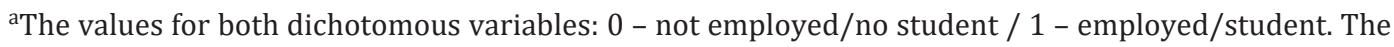
inferential statistics based on a $\chi^{2}$-test (thus $\chi^{2}$ not t-value is indicated).

${ }^{\mathrm{b}}$ The values for the ordinal education variable: 0 - no qualification / 1 - general school / 2 - secondary school / 3 - high school / 4 - bachelor's degree / 5 - master's degree or diploma level / 6 - PhD level. The inferential statistics based on a U-Test (thus z not t-value is indicated)

To examine whether the body weight of the individuals had an impact on their perception of the video material (as potential evidence of criterion validity), we calculated product-moment correlations in the stigma group between the continuous variable BMI and the indicators of construct validity (main attention was paid to negative affect, i.e. PANAS and QAVR). Subsequently, we calculated partial correlations to exclude baseline values as explaining factors again. All $p$ values were set at 0.05 .

\section{Results}

\section{Baseline Characteristics}

The participants who were randomly assigned to both conditions did not differ in any score or socioeconomic variable at baseline (table 3), suggesting that the random allocation procedure was successful overall. Only the depression scores were marginally higher in the intervention group compared to the control group $(\mathrm{t}(58)=1.83, \mathrm{p}=0.07)$.

\section{Standardized Questionnaires (Construct Validity)}

Those participants who watched the stigmatizing video reported more negative affect after the treatment than those who watched the neutral video $(\mathrm{t}(40.9)=3.37, \mathrm{p}=0.002, \mathrm{~d}=$ 1.03). Likewise, persons in the stigma condition showed more negative attitudes towards obesity after watching the video $(\mathrm{t}(58)=3.00, \mathrm{p}<0.004, \mathrm{~d}=0.86)$. In contrast, the manipulation did not trigger significant differences in the amount of perceived stress in the previous month $(\mathrm{t}(58)=0.167$, n.s.). Contrary to our expectations, depressive symptoms were more prominent in the intervention group $(\mathrm{t}(58)=2.09, \mathrm{p}=0.042, \mathrm{~d}=0.57)$. 
Table 4. Comparison between both groups after the treatment

\begin{tabular}{|c|c|c|c|c|c|c|c|c|c|c|}
\hline & \multicolumn{2}{|c|}{$\begin{array}{l}\text { Stigma video } \\
(\mathrm{n}=30)\end{array}$} & \multicolumn{2}{|c|}{$\begin{array}{l}\text { Neutral video } \\
(\mathrm{n}=30)\end{array}$} & \multicolumn{3}{|c|}{$\begin{array}{l}\text { Post-video group } \\
\text { comparison }\end{array}$} & \multicolumn{3}{|c|}{$\begin{array}{l}\text { Time-group interaction } \\
\text { (ANOVA) }\end{array}$} \\
\hline & M & SD & M & SD & $\mathrm{t}$ & $\mathrm{p}$ & $\mathrm{d}$ & $\mathrm{F}$ & $\mathrm{p}$ & $\eta^{2}$ \\
\hline \multicolumn{11}{|l|}{ Standardized questionnaires } \\
\hline Attitudes against obesity (FPS) & 54.10 & 7.39 & 48.40 & 7.31 & 3.00 & $0.004^{* *}$ & 0.86 & 10.1 & $0.002^{* *}$ & 0.153 \\
\hline Negative affect (PANAS) & 14.41 & 4.19 & 11.57 & 1.94 & 3.37 & $0.002^{* *}$ & 1.03 & 6.42 & $0.014^{*}$ & 0.103 \\
\hline Depression (BDI-V) & 37.98 & 7.85 & 33.77 & 7.82 & 2.09 & $0.042^{*}$ & 0.57 & 0.008 & 0.927 & - \\
\hline Perceived stress (PSS-10) & 15.30 & 5.34 & 15.04 & 6.38 & 0.166 & 0.868 & - & 0.116 & 0.735 & - \\
\hline \multicolumn{11}{|c|}{ Questionnaire for the assessment of video-related reaction } \\
\hline The video makes me sad & 1.97 & 1.19 & 0.07 & 0.25 & 8.56 & $<0.001^{* *}$ & 2.21 & & & \\
\hline The video makes me worried & 2.20 & 1.19 & 0.07 & 0.25 & 9.63 & $<0.001^{* *}$ & 2.48 & & & \\
\hline The video makes me contemplative & 2.40 & 1.19 & 1.03 & 0.93 & 4.96 & $<0.001^{* *}$ & 1.28 & & & \\
\hline The video makes me angry ${ }^{a}$ & 1.20 & 1.27 & 0.00 & $0.00^{\mathrm{a}}$ & 5.17 & $<0.001^{* *}$ & 0.95 & & & \\
\hline The video upsets me $\mathrm{a}^{\mathrm{a}}$ & 1.70 & 1.18 & 0.00 & $0.00^{\mathrm{a}}$ & 7.90 & $<0.001^{* *}$ & 1.44 & & & \\
\hline $\begin{array}{l}\text { If an overweight person watches the } \\
\text { video, he will find it very unpleasant }\end{array}$ & 3.03 & 0.85 & 0.73 & 0.91 & 10.1 & $<0.001^{* *}$ & 2.61 & & & \\
\hline
\end{tabular}

$\mathrm{M}=$ Mean; SD = standard deviation; independent, two-tailed t-tests between both conditions; $\mathrm{d}$ = Effect size Cohen's d; timegroup interaction of the repeated ANOVA; $\eta^{2}=$ effect size $\eta^{2}$.

$* \mathrm{p}<0.05^{* *} \mathrm{p}<0.01$.

${ }^{\text {a }}$ Due to variance restriction in the control group, the calculation of the effect size was based on the SD of the stigma group.

Overall, the time-group interaction analyses confirmed the findings from the post-video comparison (table 4): There was a significant difference between both groups in the change of negative affect $\left(F(1,56)=6.42, p=0.014, \eta^{2}=0.103\right)$ and attitudes against obesity $(F(1,56)$ $\left.=10.1, \mathrm{p}=0.002, \eta^{2}=0.153\right)$, but not in the extent to which the participants perceived stress $(F(1,56)=0.116$, n.s.) in the previous month (fig. 1$)$. There was only one exception: no timegroup interaction was registered for depressive symptoms $(F(1,56)=0.008$, n.s.). This suggests that the marginally significant baseline values (reported above) were largely responsible for the group differences after the treatment.

\section{QAVR (Construct Validity)}

The QAVR underscored the impact of the video manipulation by specifying its effects on certain parameters of negative affect (table 4). The feedback revealed that the stigmatizing video made its viewers considerably sadder $(\mathrm{t}(31.6)=8.56, \mathrm{p}<0.001, \mathrm{~d}=2.21)$, more worried $(\mathrm{t}(31.6)=9.63, \mathrm{p}<0.001, \mathrm{~d}=2.48)$, more upset $(\mathrm{t}(29)=7.90, \mathrm{p}<0.001, \mathrm{~d}=1.44)$, more angry $(\mathrm{t}(29)=5.17, \mathrm{p}<0.001, \mathrm{~d}=0.95)$, and more contemplative $(\mathrm{t}(58)=4.96, \mathrm{p}<0.001, \mathrm{~d}=1.28)$ than the neutral video. In addition, participants stated that individuals with obesity may feel unpleasant watching such a video $(\mathrm{t}(58)=10.1, \mathrm{p}<0.001, \mathrm{~d}=2.61)$. While the answers in the control group were predominantly located in lower regions of the self-developed scale (0-1), the mean values in the intervention group were primarily in the middle of the scale (1.5-2.5). Accordingly, the recorded effect sizes were quite large [42].

\section{The Role of Body Weight (Criterion Validity)}

Our data (table 5) did not reveal a substantial association between the participants' BMI and scores on the FPS $(\mathrm{r}(28)=-0.336, \mathrm{p}=0.070)$. The same result was found after controlling for corresponding pre-video values $(\mathrm{r}(27)=-0.268$, n.s.). Furthermore, the negative affect 


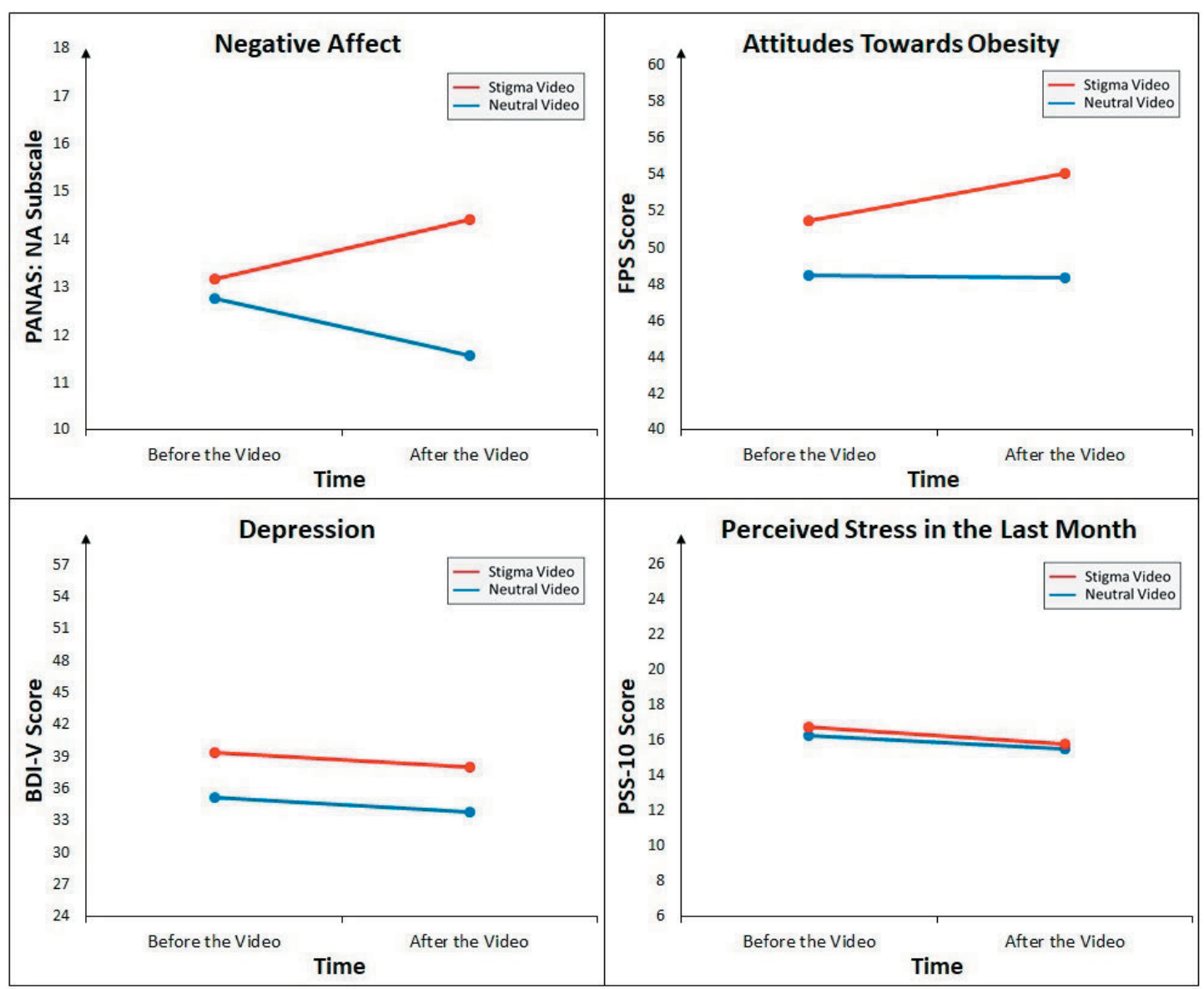

Fig. 1. The time-group interaction for the measures of negative affect and attitudes towards obesity as indicators of construct validity (upper row) as well as for the measures of depression and stress in the last month as indicators of discriminant validity (lower row).

subscale of the PANAS instrument was not substantially related to a higher BMI $\operatorname{rr}(28)=$ $0.350, p=0.058$ ). After partialling out baseline values, this relationship slightly increased and became statistically significant $(\mathrm{r}(27)=0.383, \mathrm{p}=0.040)$. Among the QAVR questions, the correlations with the amount of anger $(r(28)=0.479, p=0.007)$ and upset $\operatorname{rr}(28)=0.371$, $\mathrm{p}=0.043$ ) were statistically significant and considerable in magnitude. The participants' selfreport of being worried $(r(28)=0.294, p=$ n.s. $)$, contemplative $(r(28)=0.273, p=$ n.s. $)$, or sad $(\mathrm{r}(28)=0.173, \mathrm{p}=$ n.s. $)$ showed no generalizable relationship with the BMI.

\section{Discussion}

The results of our validation study strongly indicate the validity of the video tool. An important reason for these positive results may stem from the way we developed the videos with expert and novice feedback. Central to assessing the appropriateness of the video-based stigma manipulation was the successful testing of construct validity in a subsequent experimental study. As hypothesized, the videos caused significant differences in terms of negative attitudes against overweight and a negative affect after the treatment. Importantly, even the 
Table 5. Correlations between body mass index and the central criteria of construct validity

\begin{tabular}{|c|c|c|c|c|}
\hline & \multicolumn{4}{|c|}{ Stigma video $(n=30)$} \\
\hline & \multicolumn{2}{|c|}{$\begin{array}{l}\text { product-moment } \\
\text { correlations }\end{array}$} & \multicolumn{2}{|c|}{$\begin{array}{l}\text { partial correlations } \\
\text { (controlled for baseline values) }\end{array}$} \\
\hline & $\mathrm{r}$ & $\mathrm{p}$ & $\mathrm{r}$ & $\mathrm{p}$ \\
\hline \multicolumn{5}{|l|}{ Standardized questionnaires } \\
\hline Attitudes against obesity (FPS) & -0.336 & 0.070 & -0.268 & 0.160 \\
\hline Negative affect (PANAS) & 0.350 & 0.058 & $0.383^{*}$ & $0.040^{*}$ \\
\hline Depression (BDI-V) & 0.039 & 0.836 & 0.245 & 0.199 \\
\hline Perceived stress (PSS-10) & -0.174 & 0.357 & 0.049 & 0.803 \\
\hline \multicolumn{5}{|c|}{ Questionnaire for the assessment of video-related reaction } \\
\hline The video makes me sad & 0.173 & 0.361 & & \\
\hline The video makes me worried & 0.273 & 0.144 & & \\
\hline The video makes me contemplative & 0.294 & 0.115 & & \\
\hline The video makes me angry & 0.479 & $0.007^{* *}$ & & \\
\hline The video upset me & 0.371 & $0.043^{*}$ & & \\
\hline $\begin{array}{l}\text { If an overweight person watches the } \\
\text { video, he will find it very unpleasant }\end{array}$ & 0.087 & 0.648 & & \\
\hline
\end{tabular}

demands for the effect sizes $(\mathrm{d}>0.80)$ were met for all central variables. The QADC could specify that the stigma video made the participants sadder, more worried, angry, upset and contemplative at the same time. Depending on the treatment condition, participants also had different estimates regarding the extent to which persons with overweight would feel unpleasant after watching the corresponding video. Our data suggests that the intensity of the depicted stigmatizations as well as the empathic skills of the participants were sufficient to transport stigma-related emotions through video clips. Notably, the mean values of this question differed by more than the half of the whole scale $(\Delta M=2.30, d=2.61)$. This must be interpreted as a strong indicator for the convergent validity of the instrument. Simultaneously, the experiment provided evidence for discriminant validity of the video tool: The parameters of perceived stress in the previous month and depression, which were both conceived as situation-independent indicators with a certain temporal stability, did not considerably change.

Furthermore, our data suggests that the BMI could play a pivotal role for the evaluation of the stigma video. Two out of six indicators of the QAVR reached statistical significance. Accordingly, it is justifiable to generalize that individuals with a higher BMI felt substantially more angry and upset as a reaction to the stigma video. As argued in the introduction, this result can be well explained by Social Identity Theory [38]. However, contrary to our expectations, four indicators were not significantly related to BMI. Resulting from these findings, we can report only weak evidence for criterion validity of the instrument.

For reasons of ecological validity, we decided to include video clips of both men and women because most media and video material normally depicts both genders when dealing with obesity [37]. However, researchers such as Schvey et al. [36] highlighted the importance of gender-specific contents when it comes to developing a stigma video intervention. It could thus be presumed that the manipulation would have been even stronger with a male-only video. Nonetheless, our results strongly indicate the validity of the instrument. This does not imply that the depicted gender did not matter; rather that the stimulating influence of the 
instrument was strong enough to create the intended effect with men. However, an added benefit of including both men and women in the videos is that future researcher groups could test the validity of our instrument with women as well. Against the background of recent calls for more attention to intersectionality in weight stigma research [50], future studies may also include women as well as other social categories (e.g. race) in order to compare effects.

An important advantage of the present article is that it supplied detailed information about the selected video clips. This transparency makes it easier for readers and researchers to understand the exact nature of the video manipulation. This could also help to develop similar video-based weight stigma instruments in other languages. We even considered making the video instrument fully accessible, for example by placing it on an internet platform. However, we decided against this because of the risks of an improper use. Instead, we will provide the video material upon mail request.

In contrast to other previous instruments, our video contains a substantial amount of physical activity-related stigma material. We therefore invite researchers to use our developed instrument in experimental studies on physical activity with men, a population that has been widely neglected so far. From our point of view, middle-aged men deserve particular attention since they show considerably low activity levels [24] and weight stigma has not yet been analyzed as a causal factor.

\section{Limitations of this Study}

First, our recruited sample showed a right-skewed age distribution with a comparably high educational standard. Another related shortcoming may lie in the fact that we advertised the study as being conducted by the Institute of Sport Science. Even though we only identified it as memory test, this could have attracted primarily those individuals who are interested in exercise and physical activity. Second, we did not include a more objective indicator for weight stigma. A previous study employed saliva-based cortisol measurements which could significantly discriminate between the stigma and neutral condition [36]. Another solution would be to test implicit attitudes. For instance, the Implicit Association Test [51] has already been successfully used in the context of weight stigma [52,53] and should be taken into consideration for future validations. Third, the QDAC was a self-developed and non-validated instrument. This notwithstanding, we applied it because to our knowledge the existing literature provides no instrument for the operationalization of the intensity of stigma experienced in concrete situations such as watching a stigma video. Fourth, our male participants had to report perceptions of a '42-year-old woman' as part of the weight stigma measure (German Fat Phobia Scale). Although our results suggest that the manipulation worked, it would have been better to change the vignette to a '42-year-old man'. As a result of these limitations, we report the data as pilot validation of the instrument, and thus invite other researchers to test the instrument for further validity.

\section{Conclusion}

The goal of this study was to create a video-based instrument for the experimental manipulation of physical activity-related weight stigma in German language. Content and face validity was assured by using an expert and novice feedback during the video development phase. A subsequent experiment provided strong evidence of construct and initial evidence of criterion validity of the tool. We invite researchers in the German-speaking area to use our videos for studying the effects of weight stigma on physical activity behavior. For instance, it 
Carl et al.: Stimulating Weight Stigma in Future Experimental Designs on Physical Activity - Development and Pilot Validation of a Video Instrument

would be an interesting issue to investigate the impact of weight stigma on the amount of physical activity, quantifiable through participation rates or number of steps, or on the acquisition of sport skills (motor learning). We also invite researchers worldwide to use our procedure to develop similar instruments in other languages.

\section{Acknowledgments}

We would like to thank Dr. Rebecca Puhl and Dr. Mary Himmelstein from the Uconn Rudd Center for Food Policy and Obesity, The University of Connecticut. They generously provided insight into their video manipulation. Additionally, we would like to thank Roman Zehl, now employed at The University of Bern, Switzerland, for helping us execute the study. Institutional review board approval for the study was received from the ethics commission of the Faculty of Economics and Social Sciences (reference number B2.5.4_aa) of the University of Tübingen, Germany. The study was conducted according to the Helsinki Declaration of 1975.

\section{Disclosure Statement}

The study was self-funded. The authors declare no conflict of interest.

\section{References}

1 Guh DP, Zhang W, Bansback N, Amarsi Z, Birmingham CL, Anis AH: The incidence of co-morbidities related to obesity and overweight: a systematic review and meta-analysis. BMC Public Health 2009;9:88.

$\checkmark 2$ Fogelholm M, Kukkonen-Harjula K: Does physical activity prevent weight gain - a systematic review. Obes Rev 2000;1:95-111.

-3 Donnelly JE, Blair SN, Jakicic JM, Manore MM, Rankin JW, Smith BK: American College of Sports Medicine Position Stand. Appropriate physical activity intervention strategies for weight loss and prevention of weight regain for adults. Med Sci Sport Exerc 2009;41:459-471.

4 Health and Social Care Information Centre: Statistics on Obesity, Physical Activity and Diet. 2016: http:// content.digital.nhs.uk/catalogue/PUB20562/obes-phys-acti-diet-eng-2016-rep.pdf (last accessed May 14, 2018).

-5 Laurson KR, Lee JA, Gentile DA, Walsh DA, Eisenmann JC: Concurrent associations between physical activity, screen time, and sleep duration with childhood obesity. ISRN Obes 2014;2014:204540.

6 McIntosh T, Hunter DJ, Royce S: Barriers to physical activity in obese adults: a rapid evidence assessment. J Res Nurs 2016;21:271-287.

7 Papadopoulos S, Brennan L: Correlates of weight stigma in adults with overweight and obesity: a systematic literature review. Obesity (Silver Spring) 2015;23:1743-1760.

8 Puhl RM, Moss-Racusin CA, Schwartz MB, Brownell KD: Weight stigmatization and bias reduction: perspectives of overweight and obese adults. Health Educ Res 2008;23:347-358.

-9 Giel KE, Zipfel S, Alizadeh M, Schäffeler N, Zahn C, Wessel D, Hesse F, Thiel S, Thiel A: Stigmatization of obese individuals by human resource professionals: an experimental study. BMC Public Health 2012;12:525.

10 Vatanian LR, Novak SA: Internalized societal attitudes moderate the impact of weight stigma on avoidance of exercise. Obesity (Silver Spring) 2011;19:757-762.

11 Puhl RM, Heuer CA: Obesity stigma: important considerations for public health. Am J Public Health 2010;100: 1019-1028.

12 Puhl RM, Luedicke J, Heuer C: Weight-based victimization toward overweight adolescents: observations and reactions of peers. J Sch Health 2011;81:696-703.

13 Flint SW, Reale S: Weight stigma in frequent exercisers: overt, demeaning and condescending. J Health Psychol 2018;23:710-719..

14 Latner JD, Wilson GT, Jackson ML, Stunkard AJ: Greater history of weight-related stigmatizing experience is associated with greater weight loss in obesity treatment. J Health Psychol 2009;14:190-199.

15 Pearl RL, Dovidio JF, Puhl RM, Brownell KD: Exposure to weight-stigmatizing media: effects on exercise intentions, motivation, and behavior. J Health Commun 2015;20:1004-1013.

16 Pearl RL, Puhl RM, Dovidio JF: Differential effects of weight bias experiences and internalization on exercise among women with overweight and obesity. J Health Psychol 2015;20:1626-1632.

17 Jackson SE, Steptoe A: Association between perceived weight discrimination and physical activity: a population-based study among English middle-aged and older adults. BMJ Open 2017;7:e014592. 
Carl et al.: Stimulating Weight Stigma in Future Experimental Designs on Physical Activity - Development and Pilot Validation of a Video Instrument

18 Lewis S, Thomas SL, Blood RW, Castle DJ, Hyde J, Komesaroff PA: How do obese individuals perceive and respond to the different types of obesity stigma that they encounter in their daily lives? A qualitative study. Soc Sci Med 2011;73:1349-1356.

19 Vartanian LR, Shaprow JG: Effects of weight stigma on exercise motivation and behavior: a preliminary investigation among college-aged females. J Health Psychol 2008;13:131-138.

-20 Hübner C, Baldofski S, Zenger M, Tigges W, Herbig B, Jurowich C, Kaiser S, Dietrich A, Hilbert A: Influences of general self-efficacy and weight bias internalization on physical activity in bariatric surgery candidates. Surg Obes Relat Dis 2015;11:1371-1376.

-21 Puhl R, Suh Y: Health consequences of weight stigma: implications for obesity prevention and treatment. Curr Obes Rep 2015;4:182-190.

-22 Inderstrodt-Stephens J, Acharya L: 'Fat' chicks who run: stigma experienced by 'overweight' endurance athletes. J Sport Soc Issues 2018;42:49-67.

23 Galdas PM, Cheater F, Marshall P: Men and health help-seeking behaviour: literature review. J Adv Nurs 2005; 49:616-623.

24 Garfield CF, Isacco A, Rogers TE: A review of men's health and masculinity. Am J Lifestyle Med 2008;2:474487.

25 Lewis S, Thomas SL, Hyde J, Castle DJ, Komesaroff PA: A qualitative investigation of obese men's experiences with their weight. Am J Health Behav 2011;35:458-469.

26 Ruggs EN, King EB, Hebl M, Fitzsimmons M: Assessment of weight stigma. Obes Facts 2010;3:60-69.

27 Crandall CS, D’Anello S, Sakalli N, Lazarus E, Nejtardt GW, Feather N: An attribution-value model of prejudice: anti-fat attitudes in six nations. Pers Soc Psychol B 2001;27:30-37.

28 Puhl R, Latner J, O’Brien K, Luedicke J, Danielsdottir S, Forhan M: A multinational examination of weight bias: predictors of anti-fat attitudes across four countries. Int J Obes 2015;39:1166-1173.

29 Vartanian LR, Porter AM: Weight stigma and eating behavior: a review of the literature. Appetite 2016;102: 3-14.

-30 Aubie CD, Jarry JL: Weight-related teasing increases eating in binge eaters. J Soc Clin Psychol 2009;28:909936.

31 Major B, Hunger JM, Bunyan DP, Miller CT: The ironic effects of weight stigma. J Exp Soc Psychol 2014;51: 74-80.

32 Himmelstein MS, Incollingo Belsky AC, Tomiyama AJ: The weight of stigma: cortisol reactivity to manipulated weight stigma. Obesity (Silver Spring) 2015;23:368-374.

33 Hughes R, Huby M: The application of vignettes in social and nursing research. J Adv Nurs 2002;37:382-386.

-34 Schvey NA, Puhl RM, Brownell KD: The impact of weight stigma on caloric consumption. Obesity (Silver Spring) 2011;19:1957-1962.

-35 Donlon MM, Ashman 0, Levy BR: Re-vision of older television characters: a stereotype-awareness intervention. J Soc Issues 2005;61:307-319.

-36 Schvey NA, Puhl RM, Brownell KD: The stress of stigma: exploring the effect of weight stigma on cortisol reactivity. Psychosom Med 2014;76:156-162.

-37 Ata RN, Thompson JK: Weight bias in the media: a review of recent research. Obes Facts 2010;3:41-46.

-38 Puhl RM, Brownell KD: Psychosocial origins of obesity stigma: toward changing a powerful and pervasive bias. Obes Rev 2003;4:213-227.

39 Hogg MA, Terry DJ, White KM: A tale of two theories: a critical comparison of identity theory with social identity theory. Soc Psychol Quart 1995;58:255-269.

-40 Durso LE, Latner JD: Understanding self-directed stigma: development of the weight bias internalization scale. Obesity (Silver Spring) 2008;16:80-86.

41 Schmalz DL: 'I feel fat': weight-related stigma, body esteem, and BMI as predictors of perceived competence in physical activity. Obes Facts 2010;3:15-21.

42 Cohen J: Statistical Power for the Social Sciences. Hillsdale, Laurence Erlbaum and Associates, 1988.

-43 Faul F, Erdfelder E, Buchner A, Lang A-G: Statistical power analyses using G*Power 3.1: tests for correlation and regression analyses. Behav Res Methods 2009;41:1149-1160.

-44 Krohne HW, Egloff B, Kohlmann C-W, Tausch A: Untersuchungen mit einer deutschen Version der' Positive and Negative Affect Schedule'(PANAS). Diagnostica 1996;42:139-156.

45 Schmitt M, Maes J: Simplification of the Beck-Depression-Inventory (BDI). Diagnostica 2000;46:38-46.

-46 Schmitt M, Altstötter-Gleich C, Hinz A, Maes J, Brähler E: Normwerte für das vereinfachte Beck-DepressionsInventar (BDI-V) in der Allgemeinbevölkerung. Diagnostica 2003;52:51-59.

-47 Stein J, Luppa M, Ruzanska U, Sikorski C, König H-H, Riedel-Heller SG: Measuring negative attitudes towards overweight and obesity in the German population - psychometric properties and reference values for the German short version of the Fat Phobia Scale (FPS). PloS One 2014;9:e114641.

-48 Klein EM, Brähler E, Dreier M, Reinecke L, Müller KW, Schmutzer G, Wölfling K, Beutel ME: The German version of the Perceived Stress Scale - psychometric characteristics in a representative German community sample. BMC Psychiatry 2016;16:159-168.

49 Little RJ, Rubin DB: Statistical analysis with Missing Data. New York, John Wiley \& Sons, 2002.

50 Himmelstein MS, Puhl RM, Quinn DM: Intersectionality: an understudied framework for addressing weight stigma. Am J Prev Med 2017;53:421-431. 
51 Greenwald AG, McGhee DE, Schwartz JL: Measuring individual differences in implicit cognition: the implicit association test. J Pers Soc Psychol 1998;74:1464-1480.

52 Carels RA, Young KM, Wott CB, Harper J, Gumble A, Oehlof MW, Clayton AM: Weight bias and weight loss treatment outcomes in treatment-seeking adults. Ann Behav Med 2009;37:350-355.

53 Phelan SM, Dovidio JF, Puhl RM, Burgess DJ, Nelson DB, Yeazel MW, Hardeman R, Perry S, Ryn M: Implicit and explicit weight bias in a national sample of 4,732 medical students: the medical student CHANGES study. Obesity (Silver Spring) 2014;22:1201-1208. 